\title{
SELF-CERTIFICATION IN LAY MIDWIVES' ORGANIZATIONS: A VEHICLE FOR PROFESSIONAL AUTONOMY
}

\author{
IRENE H. BuTteR ${ }^{1}$ and BONNIE J. KAY ${ }^{2}$ \\ 'Department of Public Health Policy and Administration, School of Public Health, \\ University of Michigan, Ann Arbor, MI 48109-2029, U.S.A. and \\ 21405 Beechwood Drive, Ann Arbor, MI 48103, U.S.A.
}

\begin{abstract}
The recent resurgence of lay midwifery in the United States has been intimately connected with the establishment of grassroots organizations which address women's health issues and make the reappearance of the lay midwife a different kind of phenomenon than was the case earlier in this century. This paper describes the organizational structure of 32 lay midwives' organizations and compares them to a model of alternative women's health groups as well as more traditional health professional organizations. Are lay midwives' groups the beginnings of new professional organizations which eventually will become part of the dominant system or do they model themselves more closely after alternative women's health groups? Voluntary self-certification in five lay midwives' groups is described in detail as a means of determining how a group handles the question of integration with or separation from the existing medical care system. Certification plays a critical role in promoting acceptance and credibility of midwifery practice and is seen increasingly as a mechanism to preempt regulation by another body.
\end{abstract}

Key nords-lay midwife, certification, organizational structure

\section{INTRODUCTION}

The organization and delivery of obstetrical care in the United States has undergone dramatic changes over the last several decades and the situation remains dynamic. Examples include $99 \%$ in-hospital births, widespread use of medical technology, a dramatic rise in malpractice suits and the associated decrease in supply of services delivered by obstetricians. Concurrent with these changes has been the resurgence of lay* midwifery and the appearance of grassroots organizations of midwives and advocates of homebirth.

Grassroots midwives' organizations presently exist in all regions of the United States. This situation contrasts sharply with that at the turn of this century. We have found no record of regional or national organizations of non-nurse midwives, the dominant homebirth attendents, during this period. Whether located in urban or rural areas, women then practiced in cultural, geographic and professional isolation so

*'Lay midwife' refers to someone who practices in a home setting and who has been trained in a variety of ways, often not linked to formal programs in educational institutions but including substantial clinical training in apprenticeships. Alternative titles include independent midwife, direct entry midwife, and non-nurse midwife although some do have RN degrees. They are distinguished from certified nurse midwives who are RNs with additional training and certification in midwifery and who usually practice in hospital settings.

+For a thorough historical account of the emerging obstetrics professional organization and its effect on midwifery see Eakins P. The American Way of Birth, Part I: The Medicalization of Birth. Temple University Press, Philadelphia, PA, 1986. that the individual midwife had to be her own source of information and emotional support.

Lay midwives were often older women, recent immigrants or members of minority groups, who had large families themselves. Their training was a result of observation and experience. Immigrants brought skills from their home countries where midwifery and homebirth were widely practiced. Black women in the south (Granny midwives) were self-trained and were frequently the only choice of birth attendant for women who, because of racial discrimination, were excluded from hospital care. Relatively little cognitive knowledge was available about reproduction and the birth process to physicians and midwives. A strongly proclaimed spiritual component to birth often helped rationalize the unexplainable.

Now midwives practice in an environment where extensive knowledge about human reproduction, birth, and the treatment of birth complications is widespread and the importance of prenatal care is recognized. Midwives have responded by learning about these areas in many ways including, but not limited to, observation and experience. While there remain few formal training programs specifically for non-nurse midwives at this point in time in the United States, the majority of lay midwives acquire cognitive knowledge informally through reading and a process of mutual exchange. A major educational role is played by midwives' organizations which promote cognitive as well as experiential learning opportunities.

Midwives also face a much more organized mainstream medical care delivery system. Health professional organizations, except for medicine, were in their infancy at the turn of the century.t Now, in addition to obstetricians, nurses and nurse-midwives 
have well-established professional organizations which promote, among other things, quality of care in birth and their own economic and professional self interests as formally trained health practitioners. For mainstream health professions it has become increasingly popular to establish a credentialing body within the occupation which has legal status conferred by a government authority and for the purpose of establishing requirements, standards and criteria for professional recognition. Typically, credentialing bodies impose constraints on entry into the profession in the form of educational and experience requirements, among others. They thus control access to skills and knowledge, the number of people trained to perform the work, as well as how the profession will be practiced.

Credentialing can be of governmental or of a private/voluntary nature. In both instances it usually enhances political, economic and professional interests of members of the profession, moreso than the consuming public served by the profession. Whether the particular form of credentialing chosen is licensure, registration or certification, incentives for introducing credentialing consistently originate with specific producer interest groups in contrast to consumer interest groups. The overriding goal is to achieve self-regulation and control over labor supply [1].

Given this kind of a professional climate characterized by status hierarchies, professional rivalry and fragmentation of health professional groups, how will grassroots midwife organizations adapt? Will they strive for emulation or distinction from high status, prestigious mainstream groups"**

In essence, there are three factors which contrast the present situation for lay midwives with that earlier in this century. First, organization versus isolation: midwives are now members of groups which serve educational and social support functions. Second, midwives now practice in an environment where extensive cognitive information exists about prenatal, intrapartum and postnatal phases of maternity care. Clients, women and their partners, also are more educated about the process than earlier and a considerable amount of information is available to the general public about pregnancy and birth. Third, lay midwives now practice in a frequently hostile environment with multiple critics of their qualifications, their attendance at out-of-hospital births and thcir birthing philosophy and practices.

How important are these organizations to the survival of lay midwives and the support of homebirth? Are these groups the beginnings of a newcomer amongst health professional organizations, the purpose of which is to carve out a new niche in the existing health care system, a counterpart to chapters of the American College of Nurse Midwives? Or are they different types of organizations, more like alternative women's health groups which emerged in the

*See LeVeen D. Unionizing midwifery in California. In The American Way of Birth (Edited by Eakins P.). Temple University Press. Philadelphia. PA, 1986, for an interesting case study of nurse-midwives in California describing the pressures of integration into the established medical system. 60s and 70s and formed the basis of the Women's Health Movement? These organizations have been studied in the literature and their continued existence, as alternatives, has been documented, providing a viable point of reference [2]. The organizations which form the basis of this study were formed in the late 70 s and early 80 s. We ask: What role do they play in determining the character and continuing existence of lay midwifery and homebirth as a birthing alternative? Will midwives' groups be coopted into the impersonalized bureaucracy of the dominant medical care system or can they survive as proponents of an alternative to hospital-based, medicalized birth?

Two hypotheses are formulated as a vehicle for addressing these questions. They are:

(1) Lay midwives continue to survive as alternative childbirth practitioners by forming groups which closely resemble the model of alternative women's health organizations to protect and seek recognition for the practice of alternative childbirth. Expected benefits include: the preservation of autonomous practice through enhanced professional credibility and respectability; opportunities to keep up with advances in technical and scientific knowledge through lay midwives organizations' sponsorship of conferences, newsletters, continuing education offerings and self-study materials; and an increased sense of professionalism and solidarity.

(2) Lay midwives attempt to survive as birth attendants subject to cooptation by and subordination to the mainstream medical care system, with midwives patterning their conduct and their professional organizations after the model created by medicine. This implies that midwives, instead of remaining autonomous, would become subordinate to the dominant health professions (medicine and nursing); would have to comply with formal education pathways and credentialing systems specified and regulated by the dominant health professions which may then lead to larger human capital investments and therefore monoply over access to knowledge. skills and practice of midwifery.

We examine the implications of these hypotheses by first describing a model for alternative organizations for purposes of comparison to grassroots lay midwives' organizations. Next we review the issue of self-certification, a focal activity of these groups in recent years, as an issue which potentially may serve to differentiate these organizations from conventional health professional associations.

\section{WOMEN'S HEALTH GROUPS AS ALTERNATIVE ORGANIZATIONS}

Previously we developed a model which characterized women's health groups as an arm of the Women's Movement and aimed at radical change in the way women's health was to be organized and delivered [2, p. 626]. Central to this model is a non-hierarchical organizational structure which promotes collective, consensus-based decision-making, minimizes status differentials among members and is tolerant of diverse philosophical and political views. Relationships among group members often extend beyond common interests as health practitioners or 
health advocates and the group functions as a source of considerable social and emotional support. Members share a common philosophy and set of values surrounding women's health. Key themes are the need for clients to be informed participants in their own health care, to take responsibility for their health, to exercise their right in decision making and to demand control over their bodies. The term empowerment is often used and the concept goes beyond possessing information about one's body and one's health and practicing self-help; in addition, it means being able to confront health care institutions from a position of knowledge and strength which enables effective advocacy of their rights as health care consumers. The dominant health system is criticized for denying women autonomy and decision-making power.

This model provides a contrast with mainstream health professional organizations which tend to be bureaucratic, with concentration of power and a hierarchy of organizational positions. Their purposes are more formalized and more closely tied to advancing economic and professional interests of members and monopolizing labor supply through entry restrictions. As health professional organizations, they are part of the dominant system with deeply entrenched hierarchical and power relationships.

Using our alternative model as a framework, we surveyed lay midwives' grassroots organizations to assess its applicability in the context of the present day health care system. We report the findings in what follows.

\section{METHODOLOGY AND FINDINGS OF NATIONAL SURVEY}

A two-phase survey was developed of local and regional midwives' organizations. Phase 1 was a short, mail questionnaire requesting information about group structure, membership, purpose and function. An initial list of respondents was formed from a previous national survey of alternative women's organizations [2] and names and addresses provided by the Midwives' Alliance of North American (MANA), the national network organization. Other local groups were identified by respondents who were requested to list networks and coalitions to which they belonged. A total of 47 organizations were thus identified representing 42 states and Ontario. We could find no record of any midwife organization in nine states including the District of Columbia. These states were geographically widely scattered. Questionnaires were mailed in June, 1986 with a follow-up request sent in October.

Phase 2 was a longer mail questionnaire focusing on the process of certifying practicing midwives. In January, 1988 we mailed questionnaires to those lay midwives' organizations whose responses to Phase 1 suggested they had or were considering developing certification procedures. Seventeen organizations in as many states were included in this part of the survey. MANA reports that a lay midwife certification process had been developed in approx. 15 states by the end of 1988 [3]. We selected the issue of certification because preliminary study [4] suggested it to be of increasing interest and controversy among groups and one which illustrated how a group han- dled the question of integration with or separation from the existing medical care system.

\section{Phase I findings}

Replies were received from 34 groups in 29 states and Ontario. This number includes two groups of two members each who practiced midwifery as partners and one group which we considered a support group for midwives attending homebirth. With the exception of the latter, all groups had a majority of members who were practicing midwives. We included the two partnerships either because they represented a state where no statewide organization existed or they were tied into other regional lay midwives' networks.

How well do these organizations fit the alternative women's health group model? Although our initial list of groups included some from a previous study of alternative women's health organizations [2], most groups had not been contacted before the surveys reported here. Within the constraints imposed by a relatively brief questionnaire, our alternative group model provided a generally accurate description of the majority of groups surveyed. Midwives' groups were inclusive in their membership policies asking only that members subscribe to a philosophy of childbirth which differs sharply from the mainstream model of hospital-based childbirth. The following dimensions of this philosophy stand out as most important: midwives emphasize that birth is a family event in contrast to physicians perception of it as a medical event; they have a wellness orientation in contrast to crisis orientation; emphasis is on normalcy of a natural process (with complications expected to be rare) compared to emphasis on the riskiness of birth, no matter how infrequent; midwives use a holistic approach (body and mind are one) compared to a technological approach directed primarily at the body; midwives use passive management as distinguished from active management; midwives share knowledge and responsibility with clients in contrast to knowledge and responsibility concentrated in the provider who typically expects birthing women to assume the passive sick role; finally, midwives provide individualized in contrast to routinized care. The overall difference between the two orientations stems from the fact that obstetrics is an intervention oriented surgical specialty practiced in a sickness oriented hospital environment, whereas midwifery is primarily a supportive, non-interventionist approach which facilitates a natural event while allowing the birthing woman to be in charge of where, how and in whose company the birth should take place $[3$, p. 230].

In keeping with an inclusive membership policy, the majority of groups $(58 \%)$ placed no restrictions on membership other than support of midwifery and homebirth. Another $21 \%$ limited membership to those who assisted at birth including certified nurse midwives and physicians while $18 \%$ were composed only of lay midwives and their apprentices. This last subgroup is more exclusionary in its membership and at least superficially, resembles mainstream health professional organizations. On the other hand, membership is regarded in very personal terms unlike bureaucratic organizations [4]. The group is looked to 
for social and emotional support by midwives working in isolation from each other. Common experiences are what bind members together and those are often best shared among lay midwives. As one midwife put it: ..."We've a group that gets no acceptance from society whatsoever. We know we only get it from each other ..." $[4$, p. 232].

The extent to which lay midwife groups are hierarchical was difficult to determine because groups varied in their geographical constituencies. Some represented state-wide networks and had more formal processes for meeting and carrying out group functions. Others were more localized and less formal. Previous work [2, pp. 628-629] suggests that smaller alternative groups tend to be collectivist in nature using consensus as a basis for making group decisions. When groups become larger and their members more dispersed, the consensus process becomes too unwieldly, and steering committees and task-oriented subcommittees are formed to get business taken care of in a more timely fashion.

Over half $(52 \%)$ of the groups had 30 or more members while one-fourth of the respondent groups were very small with 10 or fewer members. This suggests that many would rely on a more formalized process for group decision-making, that is, voting with majority rule rather than using consensus, using steering committees for making decisions on behalf of the group and for setting policy subject to group approval. Seven groups indicated they had steering committees.

The frequency of meeting and the number of members can indicate the degree to which the group serves a social/emotional support function for its members, more characteristic of alternative women's groups. Those with $\mathbf{3 0}$ or more members met at most quarterly. Three met annually, another bimonthly. One group's steering committee met monthly while the entire group came together once a year. Those with less than 30 members tended to meet more frequently ranging from weekly (a group of 4) to annually with monthly meetings constituting the norm. The smaller groups with more localized membership and more frequent meetings provide the best fit of the model of this characteristic.

In balance, group size and meeting frequency would appear to support the more formal, less personalized bureaucratic organizational model. There is, however, one feature of midwives' groups which is distinctly different from women's health groups from which our alternative model was formulated. The lay midwives we are describing work alone or with a partner for the most part. Women's health groups carried out their work (operating clinics or information referral services) as a group. Group size may thus not carry the same significance for lay mid. wives' groups. For example, from our case study of the Michigan Midwives Association, a group of 50 members, a majority described as the most important reason for membership the social and emotional support the group provided [4, pp. 232-233].

An in-depth examination of the internal organization of each of these groups was beyond the scope of this study. However, a majority listed purposes of their groups in terms which suggested a non-hierarchical, egalitarian group structure: skills sharing (as opposed to providing more formal opportunities for training): $85 \%$, networking: $74 \%$, sharing legal information on midwifery practice and homebirth: $73 \%$, peer review: $56 \%$, and training: $21 \%$.

While some characteristics suggest the beginnings of bureaucratic structures which resemble health professional organizations, the purpose filled by lay midwife groups is distinctly different than that behind the formation of a professional medical organization. As a distinct, essentially powerless minority, organizations are a means to assure survival as midwives and to maintain a true alternative to hospital-based birth. The motivation is not to exclude and restrict the supply of similar health workers but to assure their continued existence. The underlying feature that distinguishes them as alternative is their distinctly different philosophy toward childbirth. Assuring the existence of a true alternative to hospital-based birth is their essential purpose for existing.

\section{Phase 2 findings}

Replies were received from 11 of the 17 organizations identified for the second phase of the survey. The information collected concentrated on three aspects of self-certification: purpose, process, and stringency of eligibility requirements. Our purpose for collecting this information was twofold: (1) to compare the rigorousness of eligibility requirements and standards of practice of a voluntary self-certification process to those embodied in 10 state laws regulating the practice of lay midwifery [5]; (2) to compare the process of certification (i.e. how competence is recognized) as employed by alternative lay midwives organizations to that of traditional professional organizations. As stated before, the process of certification was chosen because it was expected to illuminate how an organization would handle integration with or separation from the mainstream medical care system. Questions of particular interest relate to the intended use external to midwives' organizations of the recognition of individual competence, and whether certification will prompt the development of status hierarchies within the midwives' organizations. Unfortunately our findings do not lead to definitive observations on these issues.

The information submitted by respondents varied in comprehensiveness, completeness and amount of detail, which in part reflected the relative state of development of the self-certification process among respondents. Overall, there is much similarity in the approach used by lay midwife organizations in the various states, even to the extent that one organization (in West Virginia) was modeling their procedures after those in another state (New Mexico).

For purposes of clarity the description of selfcertification will be based on information provided by five organizations in the following states: California, Colorado, Michigan, Oregon and Wisconsin. These groups were selected because they were most advanced in developing the process and consequently were able to provide the most detailed sets of information. We do not know exactly why midwives groups in these five states had more fully developed systems of self-certification and were ahead of other groups in that regard. Our sense is that these five groups reflected a more advanced state of 


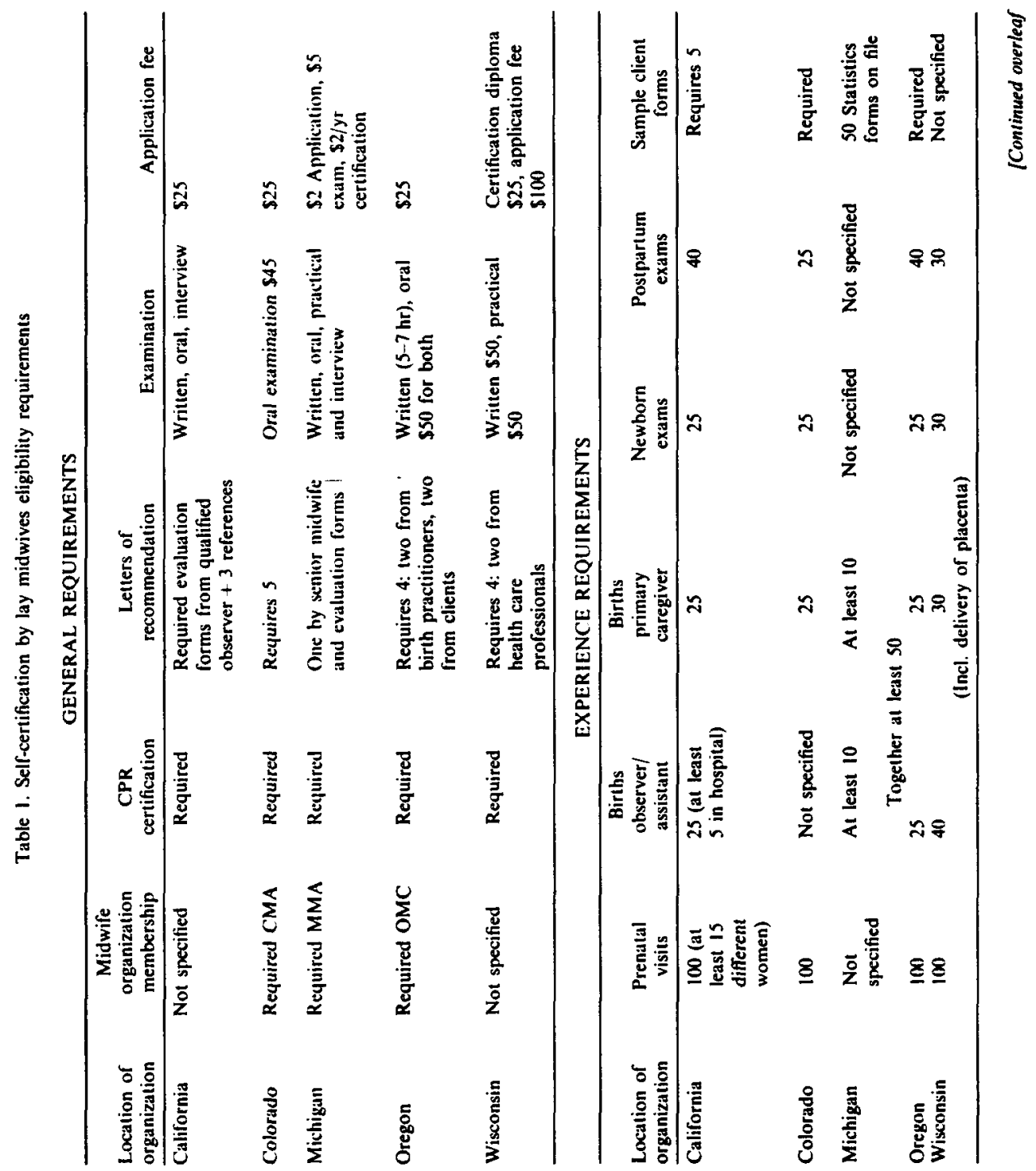




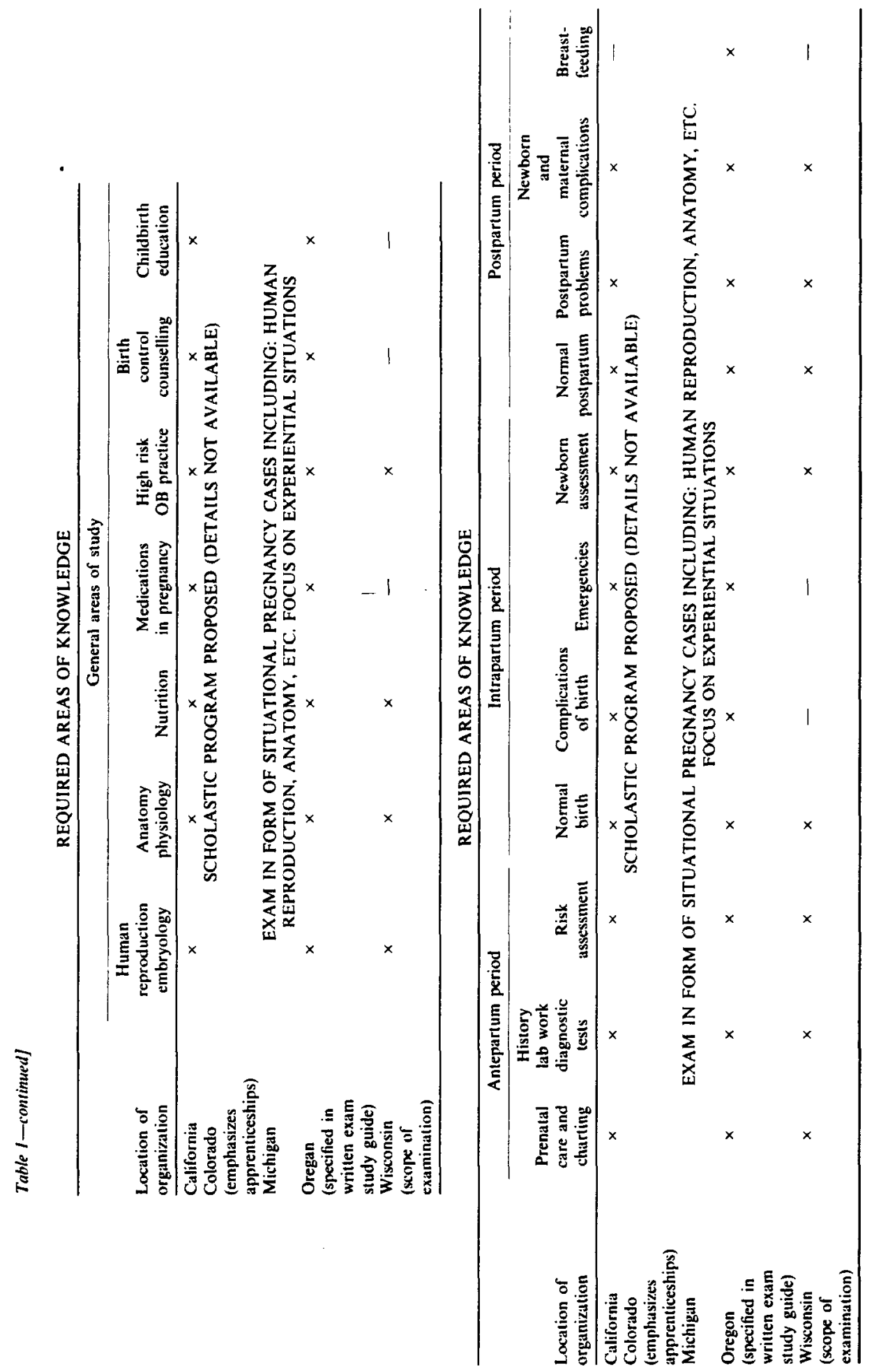




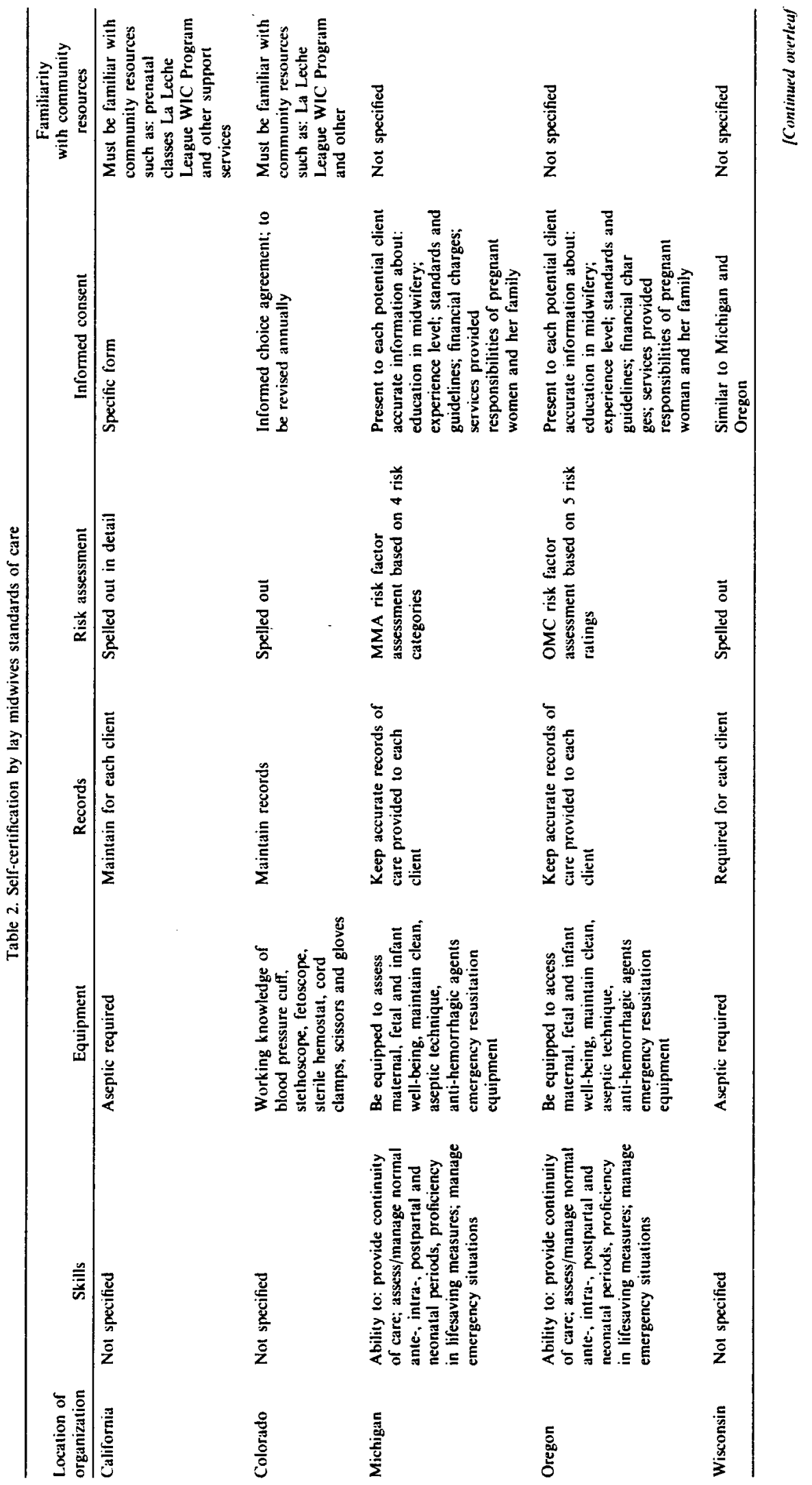




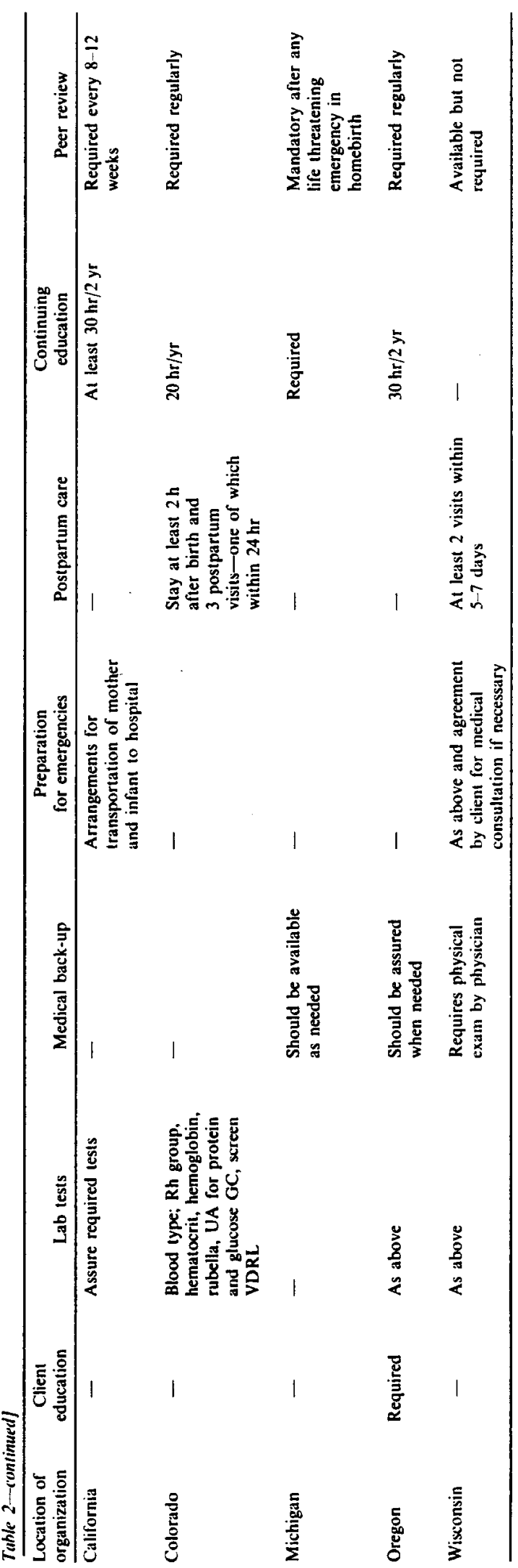


organizational development, a higher degree of connectedness with MANA and with relevant national issues and possibly a critical event within the state, such as a lawsuit filed against a lay midwife, which served to strengthen the organization and to mobilize group support. It is important to note here that selfcertification is still in its infancy as a process of midwifery development, that is was discussed and encouraged by MANA only within the last few years, and that midwife groups in many states are in the process of developing self-certification, suggesting rapid cross-fertilization from state to state.

Given the similarities found in self-certification patterns and given the tendency of more recent efforts of lay midwives' organizations to build on models developed by their predecessors, we feel confident that the picture presented is characteristic of the approach taken by these organizations in general. This pattern of uniformity is also reinforced by criteria for certification developed by MANA which qualify members of MANA to join its International Section, and then in turn, qualify the certified midwife for membership in the International Confederation of Midwives (ICM) [6].

The overall orientation of lay midwives is one which defends women's right to childbirth alternatives. This is the raison d'etre for lay midwifery practice and from it stem the purposes of selfcertification. These purposes as described by the respondents encompass the following: (1) to lend credibility and enhance the reputation of lay midwifery practice; (2) to provide standards of practice that will improve the quality and safety of homebirths; (3) to encourage growth and education of individual midwives; (4) to provide an alternative to state regulation, that is, to develop qualification and practice standards before regulation becomes externally imposed. One might say that these four purposes are driven by a single overarching purpose which is to ensure survival of lay midwifery practice and to maintain its autonomy in the future.

The certification procedures focus on two key aspects, namely, what makes a midwife eligible for certification and the standards of practice which must be upheld by certified midwives. Eligibility requirements and standards of care are presented in Tables 1 and 2 for the five respondent organizations. Table 1 shows a fair amount of consistency in terms of general and experiential requirements for certification. For example: each of the five organizations requires CPR certification, four to five letters of recommendation from birth practitioners or qualified observers, written, oral, and/or practical examinations, and having provided prenatal, intrapartum and postpartum care to 50-100 women. In addition, there are required areas of knowledge, spelled out in varying degree of detail.

There is somewhat less uniformity in standards of care as presented in Table 2. Still, each of the five respondents specifies required equipment, maintenance of records, risk assessment methods, informed consent, and peer review, and four out of five organizations describe laboratory tests and continuing education requirements. Medical backup is stipulated in three out of five states and preparation for emergencies in only two. Being able to assure medical backup is highly individualized for each midwife and almost entirely depends on her success at developing rapport and cooperation with her surrounding medical community, In states which regulate lay midwifery practice, requiring medical backup can preclude many from practice given the hostility lay midwifery receives from the established medical system [5, p. $1167 ; 7]$.

Comparing these standards of care to our previous survey of state laws and midwifery practice [5] we found a great deal of similarity between eligibility requirements and standards of practice stipulated in state statutes and those developed by lay midwives' organizations for purposes of self-certification. There are, however, some important differences which include the following aspects: eligibility requirements of state statutes are somewhat more formal compared to those of midwifery organizations which tend to be more experienced-based and concentrated on the apprenticeship route of developing qualifications; the standards of care specified for self-certification appear to be as rigorous as those upheld in state midwifery laws but the former place more emphasis on peer review by lay midwives, while the latter underscore the requirement of physician consultation and backup. While lay midwives' organizations hope that eventually all or most members will become certified, at present certification is voluntary, in contrast to mandatory certification/registration in states with midwifery laws. Both types of certification include provisions for revocation of certification on grounds of fraud, incompetency or unprofessional conduct. It is indeed not surprising to find the similarities noted above when keeping in mind the previously stated intent of midwives' organizations to develop self-certification in lieu of or before regulation becomes imposed by the state.

\section{DISCUSSION}

We undertook a survey of grassroots midwives' organizations to better understand what forces have prompted their emergence during the last decade; to determine whether these groups resembled alternative women's health organizations more closely than the model of dominant professional organizations, and to ascertain why these groups have focused their attention on certification, a concern more typical of dominant professional organizations.

In part the momentum for grassroots midwives organizations was prompted by the growing number of lay midwives during the last decade. This growth was supported by an increasing preference for outof-hospital births as a safe alternative to the norm of hospital births. While the percentage of out-ofhospital births remains small, it has been rising since the mid 70 s from around $0.5-1 \%$ of total births and from around 26,000 in 1974 to almost 37,000 in 1986 [8]. A recent study on midwife-attended births investigated the race, age, nationality, educational attainment and birth order of the mothers and found that women opting for midwife-attended out-of-hospital births tended to be white, over 30 years old, above average in educational attainment, American born, and experiencing at least the third birth. Thus it is clear that the women who choose this alternative are 
not poor, disadvantaged, or foreign born nor are they extremely young, inexperienced or counterculture [9].

In contrast to earlier periods, it will be increasingly difficult for modern midwives to survive in geographic, cultural and professional isolation given the dynamics of the current health care and maternity care system. The foremost function to be carried out by grassroots organizations and by MANA as the confederation of the state and regional groups, consists of promoting and increasing the credibility of midwifery practice. Consonant with this primary function are the following sub-functions: identifying ways for educating practicing midwives, determining entry qualifications and standards for midwifery practice, developing channels for dissemination of information as well as a network for sharing experience and for pooling energies, ideas and mutual support. Participation in the discussion of relevant health policy issues may be an added and increasingly important function. It is clear that some sort of an organization is a prerequisite for these specific functions and that the denial of these functions is likely to jeopardize survival.

We conclude from our findings that grassroots lay midwives' organizations have become critical in preserving the viability of lay midwives in their role as homebirth attendants, and moreover, that the survival of lay midwifery and homebirth is closely intertwined with preserving options for women with respect to choice between childbirth alternatives. As lay midwives become increasingly aware of the difficulties of surviving in isolation and at the periphery of the dominant system they realize the necessity to organize. From the information collected in our surveys we infer that grassroots midwives' organizations, following the footsteps of their mother organization, MANA, share more of the attributes of alternative women's health organizations than of mainstream health professional organizations. They appear to be less formal than their counterparts emphasizing flexibility and diversity. A further similarity lies in advocacy of women's empowerment, in regard to their health and the preservation of different childbirth options.

The focus on certification appears to stem from its critical role in promoting acceptance and credibility of midwifery practice. It is felt in some of these groups that members should be accountable to each other and that it is in everyone's self interest to promote and protect the reputation of the group." Certification is thus viewed as a mechanism for self

*An article by Marget Reid [10] addresses the incompatibility between alternative occupations'organizations and the supportiveness and solidarity of sisterhood. In her research on lay midwives the author identified a tendency on the part of those midwives in states with licensure statutes governing the practice of midwifery to abandon the model of alternative organization in an attempt to embrace professionalism. In our own work on lay midwife organizations, particularly the Michigan Midwife Association which is in a state where lay midwives are not licensed, we found that the members, while struggling with the same conflict, have, until now, managed to combine elements of professionalism with key components of sisterhood. promotion and self governance which, once it is put in place, could help to preempt regulation by another body. Alternatively a certification process allows midwives to negotiate with the state from a position of strength in shaping state regulation should it become inescapable.

While the content of midwives' self-certification mechanisms (as shown in Tables 1 and 2) is not appreciably different from that of state regulations or from that of more conventional health professions' associations, the process of certification is less formal, more flexible, and less authoritarian. The decision of who gets certified is made by a board or committee of volunteers, either self-selected or elected by members of lay midwives organizations, usually for a one, two, or at the most, a three-year term. The certification decision itself is based on the application, documents to support needed qualifications, and typically a written and oral examination, developed and revised by the certification board. It is important to remember that lay midwives are certifying lay midwives instead of certification by another body, which may consist of doctors, nurses, and health department officials, appointed by the government to exercise decision-making power over midwives under the auspicies of states' midwifery laws.

Finally, the purpose of certification differs. Dominant health professional organizations tend to use certification, or any form of credentialing as an exclusionary device which gives them monopoly control. In contrast, lay midwives organizations see no value in monopolistic control. As a small minority of birth attendants, larger numbers of lay midwives can only increase their visibility and promote the homebirth alternative. They view certification as a way towards professional development, advocacy and promotion of midwifery competence. For example, a key element in self-certification of lay midwives is peer review, which has the function of education, support, communication and exchange between individual midwives, in the context of strengthening and promoting the practice of their profession. By emphasizing the promotion and development of competency of individual midwives, midwives organizations aim to enhance intra-individual accountability as a way of increasing outside recognition and respectability of the entire group.

\section{REFERENCES}

1. Butter I., Carpenter E., Kay B. and Simmons R. Credentialling, gender and the health labor force. In Sex and Status: Hierarchies in the Health Workforce, Chap. 4, American Public Health Association, Washington, DC, 1985.

2. Simmons R., Kay B. and Regan C. Women's health groups: alternatives to the health care system. Int. $J$. Hlth Serv. 14, 619, 1984.

3. Midwives' Alliance of North America. MANA Newsletter 5, I Sept. 1987; 5, 3, Nov. 1987; 7, 1, March 1989.

4. Kay B., Butter I., Chang D. and Houlihan K. Women's health and social change: the case of lay midwives. Int. J. Hlth Serv. 18, 223, 1987.

5. Butter I. and Kay B. State law and the practice of midwifery. Am. J. Publ. Hlth 78, 1161, 1988.

6. Oregon Midwifery Council. Organizational and Certification Packet. La Grande, Oregon, Oct. 1986. 
7. Sullivan D. and Weitz R. Obstacles to the practice of licensed lay midwifery. Soc. Sci. Med. 19, 1189, 1984.

8. National Center for Health Statistics. Centers for Disease Control. Vital Statistics of the United States, 1986. Volume I-Natality. Washington, DC, 1988.

9. Lewis C. T. A current perspective on midwife-attended births. Paper presented at the 116 th Annual Meeting of the American Public Health Association, 13-17 Nov., 1988, Boston, MA

10. Reid M. Sisterhood and professionalization: a case study of the American midwife. In Women as Healers: Cross Cultural Perspective (Edited by Shepherd McCain C.), pp. 219-239. Rutgers University Press. New Brunswick, NJ, 1989. 